\title{
The Role of Family Expressed Emotion and Perceived Social Support in Predicting Addiction Relapse
}

\author{
Akbar Atadokht ${ }^{1, *}$; Nader Hajloo ${ }^{1}$; Masoud Karimi ${ }^{1}$; Mohammad Narimani ${ }^{1}$ \\ ${ }^{1}$ Department of Psychology, University of Mohaghegh Ardabili, Ardabil, IR Iran \\ *Corresponding author: Akbar Atadokht, Department of Psychology, University of Mohaghegh Ardabili, Ardabil, IR Iran. Tel: +98-9144529612, Fax:+98-4533510132, E-mail: atadokht@ \\ uma.ac.ir
}

Received: June 17, 2014; Revised: September 24, 2014; Accepted: October 1, 2014

\begin{abstract}
Background: Emotional conditions governing the family and patients' perceived social support play important roles in the treatment or relapse process of the chronic disease.

Objectives: The current study aimed to investigate the role of family expressed emotion and perceived social support in prediction of addiction relapse.

Patients and Methods: The descriptive-correlation method was used in the current study. The study population consisted of the individuals referred to the addiction treatment centers in Ardabil from October 2013 to January 2014. The subjects $(n=80)$ were randomly selected using cluster sampling method. To collect data, expressed emotion test by Cole and Kazaryan, and Multidimensional Scale of Perceived Social Support (MSPSS) were used, and the obtained data was analyzed using the Pearson's correlation coefficient and multiple regression analyses.

Results: Results showed a positive relationship between family expressed emotions and the frequency of relapse $(r=0.26, \mathrm{P}=0.011)$ and a significant negative relationship between perceived social support and the frequency of relapse $(r=-0.34, P=0.001)$. Multiple regression analysis also showed that perceived social support from family and the family expressed emotions significantly explained $12 \%$ of the total variance of relapse frequency.

Conclusions: These results have implications for addicted people, their families and professionals working in addiction centers to use the emotional potential of families especially their expressed emotions and the perceived social support of addicts to increase the success rate of addiction treatment.
\end{abstract}

Keywords: Expressed Emotion; Social Support; Recurrence; Substance Addiction

\section{Background}

Addiction is a psychological and behavioral syndrome with a high desire to use drugs and reuse it after stopping (1) and is considered as a physical, mental, social and spiritual illness (2). Available statistics show high rates of drug use. The number of drug users worldwide reaches 190 million people and the number of addicts in Iran reaches two million people with a mean age of 18 years (3). The overall trend shows an increase in the number of addicts over the past 40 years (4). Therefore, the growth rate of drug abuse was three times more than the population growth rate over the past 20 years in Iran (5).

According to the above statistics, prevention and rehabilitation programs were designed and implemented for drug addiction but the addicts' population remained high, especially in people who stopped their use. Addiction relapse is one of the important issues in addiction recovery (6). Some experts reported that nearly $90 \%$ of all the treated addicts experienced relapse within one year after discharge (7). Thus, efforts are vital to identify the factors affecting relapse.

As noted above, addiction is a disease in which the bio- logical, psychological, and social factors are playing major roles (8), but social factors and determinants have more basic roles in the incidence, prevalence and persistence of addiction (9). One of the social determinants is family factors especially the family's expressed emotions. Expressed emotion indicates the family emotional status that reflects the quality of relationship between the patient and his family members (10). Family emotional environment against the disease is very important and quality of family emotional atmosphere affects the disease recovery and treatment (11). Effects of family expressed emotion on illness were previously shown on schizophrenia patients. Apart from schizophrenia, there were studies which showed that the expressed emotion is associated with mood and eating disorders (11), personality disorders (12), bipolar disorder (13), anxiety disorders, and also with substance abuse (14).

The lack of proper communication with the family members (single individuals) and lack of understanding and maltreatment of husband, wife, and children (married individuals) was found as an important factor in

Copyright (C) 2015, Zahedan University of Medical Sciences. This is an open-access article distributed under the terms of the Creative Commons Attribution-NonCommercial 4.0 International License (http://creativecommons.org/licenses/by-nc/4.0/) which permits copy and redistribute the material just in noncommercial usages, provided the original work is properly cited. 
addiction relapse (3) but the change of family expressed emotion and its impact on addiction received little attention. Social support is another determinant that affects addiction. Social support is defined as social resources that non-professionals provide for the supported person in the formal context of support groups or in informal helping relationships (15).

The role of perceived social support in the prevention and treatment of drug abuse and relapse is shown in various studies. In this regard, the studies by Spoth and Redmond (16) and Blume et al. (17) suggest that the existence of supportive structures and networks, as well as supportive interventions such as spiritual and familial support have major role in promotion of treatment goals in drug abusers and prevention of relapse. Available social support affects the line of addiction and recurrence in addict people (18). Perceived social support acts as a shield against the recurrence and relapse by increasing the psychological health (19). Richardson (20) found that the presence of family members in the social network of addicts in order to prolong drug abstinence is effective one year after the detoxification. Davis and Jason (21) also concluded that there was a positive relationship between drug abstinence duration and receiving social support. Clients' perceptions regarding social support, improves their psychosocial functioning during the treatment process (22). Other studies also showed that during the early stages of treatment, the support of other people has important role in addiction treatment $(23,24)$. The results of the study by Hashemi et al. revealed that the people who did not relapse had better condition with respect to social support than those who did (9). In contrast, some studies (25) showed that social support cannot always predict the improvement stages. Considering the high and increasing prevalence of addiction and relapse, and gaps in the existing research on the role of expressed emotion and perceived social support on drug abuse relapse, the current study tried to answer: whether family expressed emotion and addicts perceived social support has the ability to predict relapse?

\section{Objectives}

The current study aimed to investigate the role of family expressed emotion and perceived social support in prediction of retrospective relapse of addiction among addicts.

\section{Patients and Methods}

The descriptive-correlation method was used in the current study. The study population consisted of individuals referred to addiction treatment centers in Ardabil from October 2013 to January 2014. Eighty subjects were selected from ten randomly selected centers with regard to entry criteria (lack of chronic, emotional, and cognitive problems, married for at least five years and having fam- ily, addicted to one or more substances). The study used the following instruments for data collection:

\subsection{Cole and Kazaryan Expressed Emotion Test}

This paper-based test included 60 questions with multiple-choice answers (seldom $=4$, sometimes $=3$, often $=2$, always $=1$ ) that measured the emotional responses, negative attitudes and tolerance, low/high expectations, and a total score of expressed emotions level. In each subset, the maximum score was 60 and the total score was 240 . High scores in this scale are indicative of high levels of expressed emotion. The cutoff points are reported as follows: the scores less than 116 indicate lower expressed emotion, and the scores above 150 indicate highly expressed emotion. This test was translated to Farsi by Dehqani for the first time in Iran and its internal validity was determined using Cronbach's alpha reported 0.94, $0.70,0.89,0.84$, and 0.78 , for the total scale, interruptions/intervention, emotional response, negative attitudes towards the disease, and tolerance/expectations, respectively (26).

\subsection{Multidimensional Scale of Perceived Social Support}

Zimet et al. (27) made this questionnaire to measure the extent to which an individual perceives social support from three sources: Significant Others (SO) (items 1, 2, 5, and 10), Family (FA) (items 3, 4, 8, and 11) and Friends (FR) (items 6, 7, 9, and 12). The Multidimensional Scale of Perceived Social Support (MSPSS) is a brief, easy to administer self-report questionnaire which includes twelve items rated on a seven-point Likert-type scale with scores ranging from very strongly disagree (1) to very strongly agree (7). The MSPSS has proven to be psychometrically sound in diverse samples, and to have good internal and test-retest reliability, and robust factorial validity. Overall alpha coefficient was 0.91 and its subscale alpha coefficients ranged from 0.90 to 0.95 . To analyze data, the statistical tests of Pearson's correlation coefficient and multiple regression were used on SPSS-16.

\section{Results}

Table 1 shows significant positive relationships between frequency of relapse and tolerance/expectation, negative attitude, and emotional response $(\mathrm{P}<0.05)$ but the relationship between the frequency of relapse and the emotional intervention was not significant. There were significant negative relationships between frequency of relapse and perceived social support from family, friends, and total social support $(\mathrm{P} \leq 0.01)$.

To evaluate the predictability of relapse frequency based on the expressed emotion and perceived social support, the multiple regression analysis was used and its results were reported in the subsequent tables. Table 2, shows that the frequency predicting model of relapse based 
Atadokht A et al.

on expressed emotion and perceived social support was significant and the predictor variables (expressed emotion and perceived social support) explain $21 \%$ of the relapse frequency. Table 3 shows that among the predictor variables included in the model, all variables except the perceived social support from friends and important people, had the ability to predict the relapse frequency, significantly.

Table 1. Correlation Coefficients of Expressed Emotion and Social Support Components With the Frequency of Relapse ${ }^{\text {a }}$

\begin{tabular}{|c|c|c|c|}
\hline Variables & Mean \pm SD & $\mathbf{r}$ & PValue \\
\hline Emotional intervention & $36.37 \pm 4.45$ & 0.01 & 0.93 \\
\hline Tolerance/expectation & $37.10 \pm 10.04$ & 0.25 & 0.02 \\
\hline Negative attitudes & $35.61 \pm 9.87$ & 0.22 & 0.04 \\
\hline Emotional response & $37.17 \pm 10.02$ & 0.24 & 0.03 \\
\hline Total expressed emotion & $149.37 \pm 28.27$ & 0.26 & 0.02 \\
\hline Family social support & $17.71 \pm 7.46$ & -0.37 & 0.001 \\
\hline Friends social support & $12.52 \pm 6.82$ & -0.28 & 0.01 \\
\hline $\begin{array}{l}\text { Important people social } \\
\text { support }\end{array}$ & $16.41 \pm 6.91$ & -0.14 & 0.21 \\
\hline Total social support & $46.65 \pm 16.44$ & -0.34 & 0.002 \\
\hline
\end{tabular}

${ }^{\mathrm{a}}$ r, Pearson's correlation coefficient

Table 2. Regression Analysis of Relapse Frequency, Based on Expressed Emotion and Perceived Social Support ${ }^{\text {a }}$

\begin{tabular}{lcccccc}
\hline & SS & df & MS & f & P & $\mathbf{R}^{2}$ \\
\hline $\begin{array}{l}\text { Predictive } \\
\text { Variable }\end{array}$ & & & & & & \\
Regression & 166.52 & 8 & 20.81 & 2.31 & 0.029 & 0.46 \\
Residual & 620.20 & 69 & 8.98 & & & \\
Total & 786.72 & 77 & & & & \\
\hline
\end{tabular}

${ }^{\mathrm{a}}$ Abbreviations: df, degrees of freedom; f, f-ratio; MS, mean square; P, significance; R, multi correlation; $\mathrm{R}^{2}$, R square; SS, sum of squares.

Table 3. Standardized and Non-standardized Coefficients of Predicting Relapse Frequency Based on Expressed Emotion and Perceived Social Support ${ }^{\mathrm{a}}$

\begin{tabular}{|c|c|c|c|c|c|}
\hline \multirow[t]{2}{*}{ Variables } & \multicolumn{2}{|c|}{ Non-standardized coefficients } & \multirow[t]{2}{*}{ 及 } & \multirow[t]{2}{*}{$\mathbf{t}$} & \multirow[t]{2}{*}{ P Value } \\
\hline & B & SE & & & \\
\hline Constant & 2.74 & 4.14 & & 0.66 & 0.51 \\
\hline $\begin{array}{l}\text { Important people social } \\
\text { support }\end{array}$ & 0.08 & 0.06 & 0.18 & 1.26 & 0.21 \\
\hline Family social support & -0.2 & 0.08 & -0.47 & -2.64 & 0.01 \\
\hline Friends social support & -0.05 & 0.06 & -0.096 & -7.79 & 0.43 \\
\hline Total expressed emotion & -0.88 & 0.42 & -7.83 & -2.07 & 0.04 \\
\hline Emotional intervention & 0.96 & 0.45 & 1.34 & 2.09 & 0.04 \\
\hline Tolerance/Expectation & 0.92 & 0.45 & 2.93 & 2.04 & 0.04 \\
\hline Negative attitudes & 0.87 & 0.43 & 2.72 & 2.03 & 0.04 \\
\hline Emotional response & 0.91 & 0.43 & 2.87 & 2.08 & 0.04 \\
\hline
\end{tabular}

a Abbreviations: B, Unstandardized coefficient; ß, Beta (standardized regression Coefficient); SE, Standard Error; $t$, $t$ value. 


\section{Discussion}

The current study aimed to identify the role of expressed emotion and perceived social support in predicting addiction relapse. The results showed significant positive relationships between frequency of relapse and tolerance/expectation, negative attitude, emotional response and total score of expressed emotion, but the relationship between the frequency of relapse and the emotional intervention was not significant. Thus, the increase of family expressed emotion in components of tolerance/ expectation, negative attitude, emotional response, and total expressed emotion increased the relapse frequency. The obtained results were consistent with those of Butzlaff and Hooley (11) that showed the effect of relatives expressed emotion on relapse of affective and eating disorders; Hooley (12) and Miklowitz (13) that showed the effect of family expressed emotion in improvement of personality, mood, depression and bipolar disorders; and Hooley and Parker (14) that showed expressed emotion associated with anxiety disorders and successful treatment of substance abusers.

To explain the relationship between family expressed emotion and success in treatment, it can be noted that most of the people with mental disorders refer to rehabilitation and pass it, but many people are likely to recur in the disorder. One of the factors contributing to relapse after rehabilitation is impaired family expressed emotion. High level of expressed emotion in close relatives and family of the patient leads to increased family pressure and criticism over the patients, which results in returning the person to his old form and illnesses. The pressures of negative criticism and compassion puts a heavy burden on individuals with disorder that the only way to cope with this stress and mental pressure, is regression to the past state of disease and relapse (10).

The study also showed significant negative relationships between frequency of relapse and perceived social support from family, friends and total social support. It means that the decrease of perceived social support from family, friends and total social support associated with the increase of relapses probability. The current study results were consistent with those of previous studies such as the study by Ellis et al. (18) that showed the effect of available social support in the addiction and relapse pathway of addict people and the study by Dodge and Potocky (19) that indicated the effect of perceived social support on increasing people's mental health. But these results were incongruent with the results obtained by MacDonald et al. (25) who argued that social support does not lead to improvement. These results emphasized on the fact that the existence of supportive structures and networks, as well as supportive interventions such as spiritual and familial support have major role in promotion of treatment goals among drug abusers and relapse prevention. Lack of perceived social support especially social support from family, friends and the community reduce the resistance of patients against environmental stress that in turn can lead to relapse of disease and drug abuse. Since drug abusers often feel alone, developing a support network for such people can prevent addiction relapse. Clients, by engaging in this process, feel that they have a support system when attempting to quit. Also, identifying and creating other opportunities in the social context that encourages a person to change behavior help people to develop their support networks. Lack of social support increases the likelihood of slip, and may eventually lead to relapse (28).

The major limitation of this study was gender limitation that the samples were selected only from the male. Second limitation related to regional limitation that the samples were selected only from Ardabil city. The last limitation was lack of control on drug types used by the participants. Therefore, for further studies, it is suggested that: the relationship between variables in female addicts be considered, the abused substance be controlled, subjects would be selected from different cities and even villages, finally, the study suggests that in order to increase efficiency and enhance the success rate in addiction treatment, professional should consider expressed emotion and perceived social support from family; and patients and their families should be helped to identify the patients`social support networks and become more aware of their current and potential relationships.

\section{Acknowledgements}

Authors would like to thank the officials of Ardabil addiction centers and their staff, and also all the people who honestly completed the questionnaires to have accurate results. The authors wish to thank the colleagues and all the participants in the study.

\section{Authors' Contributions}

Akbar Atadokht and Nader Hajloo were responsible for the study conception and design. Masoud Karimi performed the data collection. Akbar Atadokht performed the data analysis and was responsible for the drafting of the manuscript. Mohammad Narimani made critical revisions to the paper for important intellectual content.

\section{References}

1. Dackis C, O'Brien C. Neurobiology of addiction: treatment and public policy ramifications. Nat Neurosci. 2005;8(11):1431-6.

2. Galanter M. Innovations: alcohol \& drug abuse: spirituality in Alcoholics Anonymous: a valuable adjunct to psychiatric services. Psychiatr Serv. 2006;57(3):307-9.

3. Din Mohammadi MR, Amini K, Yazdan Khah MR. Survey of social and environmental factors related to the relapse of addiction in volunteer addicted individuals in welfare organization of Zanjan. J Zanjan Univ Med Sci. 2007;15(59):85-94

4. Vassileva J, Georgiev S, Martin E, Gonzalez R, Segala L. Psychopathic heroin addicts are not uniformly impaired across neurocognitive domains of impulsivity. Drug Alcohol Depend. 2011;114(2-3):194-200.

5. Tavakoli Ghouchani H, Shojaei Zadeh D, Mazloum SR. Comparative study of factors associated with addiction withdrawal in cli- 
ents referring to drug-stop clinics of Northern Khorasan (Iran) in 2007. Ilam Univ Med Sci. 2009;17(2):32-43.

6. Nielsen DA, Ho A, Bahl A, Varma P, Kellogg S, Borg L, et al. Former heroin addicts with or without a history of cocaine dependence are more impulsive than controls. Drug Alcohol Depend. 2012;124(1-2):113-20.

7. Naderi SH, Bina Zadeh M, Sefatian S. 1 edTehran: Medical Council Organization; 2008.

8. Rahimi A, Kaavian M. Substance abuse prevention guide for media practitioners.: Welfare Organization; 1998.

9. Hashemi T, Fotouhibonab S, Karimi HR, Beirami M. Role of irrational beliefs, perceptions, self-efficacy and social support on recurrence of substance abuse disorder. J Res Addict. 2010;4(13):7-23.

10. Marom S, Munitz H, Jones PB, Weizman A, Hermesh H. Expressed emotion: relevance to rehospitalization in schizophrenia over 7 years. Schizophr Bull. 2005;31(3):751-8.

11. Butzlaff RL, Hooley JM. Expressed emotion and psychiatric relapse: a meta-analysis. Arch Gen Psychiatry. 1998;55(6):547-52.

12. Hooley JM. Expressed emotion and relapse of psychopathology. Annu Rev Clin Psychol. 2007;3:329-52.

13. Miklowitz DJ. The Role of the Family in the Course and Treatment of Bipolar Disorder. Curr Dir Psychol Sci. 2007;16(4):192-6.

14. Hooley JM, Parker HA. Measuring expressed emotion: an evaluation of the shortcuts. J Fam Psychol. 2006;20(3):386-96.

15. Cohen SH, Gottlieb BH, Underwood LG. Social relationships and health: challenges for measurement and intervention.New York: Oxford University Press; 2000.

16. Spoth R, Redmond C. Effective recruitment of parents into family-focused prevention research: A comparison of two strategies. Psychology Health. 1994;9(5):353-70.

17. Blume TW, Green S, Joanning H, Quinn WS. Social role negotiation skills for substance-abusing adolescents: a group model.J Subst Abuse Treat.1994;11(3):197-204.
18. Ellis B, Bernichon T, Yu P, Roberts T, Herrell JM. Effect of social support on substance abuse relapse in a residential treatment setting for women. Evaluat Prog Plan. 2004;27(2):213-21.

19. Dodge K, Potocky M. Female substance abuse: characteristics and correlates in a sample of inpatient clients. J Subst Abuse Treat. 2000;18(1):59-64.

20. Richardson L. Social network characteristics and substance abuse treatment outcomes.: New School for Social Research; 1999.

21. Davis MI, Jason LA. Sex differences in social support and selfefficacy within a recovery community. Am J Community Psychol. 2005;36(3-4):259-74.

22. Chong J, Lopez D. Social networks, support, and psychosocial functioning among American Indian women in treatment. $\mathrm{Am}$ Indian Alsk Native Ment Health Res. 2005;12(1):62-85.

23. Laudet AB, Cleland CM, Magura S, Vogel HS, Knight EL. Social support mediates the effects of dual-focus mutual aid groups on abstinence from substance use. Am J Community Psychol. 2004;34(34):175-85.

24. Warren JI, Stein JA, Grella CE. Role of social support and selfefficacy in treatment outcomes among clients with co-occurring disorders. Drug Alcohol Depend. 2007;89(2-3):267-74.

25. MacDonald EM, Luxmoore M, Pica S, Tanti C, Blackman JM, Catford N, et al. Social networks of people with dual diagnosis: the quantity and quality of relationships at different stages of substance use treatment. Community Ment Health J. 2004; 40(5):451-64.

26. Dehghani SH. Expressed Emotion and Sexuality. J Fundam Ment Health. 2003;6(19-20):84-91.

27. Zimet GD, Dahlem NW, Zimet SG, Farley GK. The Multidimensional Scale of Perceived Social Support. J Personal Assess. 1988;52(1):30-41.

28. Marlatte GA, Barrett K. Relapse prevention. In: Pkleber H editor. the text book of substance abuse.. Washington D.C.: American Psychiatric Press Inc; 1994. 